\title{
Effect of Titanium Dioxide Nano Particles Incorporation on Mechanical and Physical Properties on Two Different Types of Acrylic Resin Denture Base
}

\author{
Mohamed Ashour Ahmed1', M. El-Shennawy2*, Yousef M. Althomali ${ }^{3}$, Adel A. Omar# \\ ${ }^{1}$ Prosthodontics Department, Faculty of Dentistry, Taif University, Taif, Saudi Arabia \\ ${ }^{2}$ Mechanical Engineering Department, Engineering College, Taif University, Taif, Saudi Arabia \\ ${ }^{3}$ Preventive Department, Faculty of Dentistry, Taif University, Taif, Saudi Arabia \\ Email: moha_111@yahoo.com
}

Received 24 May 2016; accepted 1 July 2016; published 5 July 2016

Copyright (C) 2016 by authors and Scientific Research Publishing Inc.

This work is licensed under the Creative Commons Attribution International License (CC BY). http://creativecommons.org/licenses/by/4.0/

(c) (i) Open Access

\section{Abstract}

The aim of this study is to clarify the effect of different concentrations of titanium dioxide nanoparticles (Nps) on the properties of two types of heat polymerized acrylic resin. The tested parameters were flexural strength, impact strength, and microhardness. The two types of acrylic resin used in this study were conventional unmodified (Implacryl, Vertex) and high impact heat polymerized acrylic resin (Vertex-Dental, Netherlands). Both types of acrylic resin were modified by using $1 \%$ and $5 \% \mathrm{TiO}_{2}$ Nps powder. Specimen's dimensions were prepared according to the American Dental Association Specification No. 12. Three types of specimens were prepared: 1) flexural strength specimens $50 \mathrm{~mm} \times 10( \pm 0.2) \mathrm{mm} \times 3( \pm 0.2) \mathrm{mm}, 2)$ impact strength test specimens $60 \mathrm{~mm} \times 6.0 \mathrm{~mm} \times 4.0 \mathrm{~mm}, 3)$ microhardnesss specimens $25 \mathrm{~mm} \times 10 \mathrm{~mm} \times 3( \pm 0.2) \mathrm{mm}$. For each test 6 groups were prepared (each group containing 5 samples). Thirty specimens were prepared in each of the three tests, amounting to a total number of 90 specimens. Mechanical properties such as flexural strength (FS), impact strength and microhardness of the above mentioned specimens were determined using universal testing machine, Izod pendulum impact testing machine and Vickers microhardness tester, respectively. ISO Specification No. 1567 was followed in microhardness test. The data was collected and statistically analyzed. Flexural strength considerably decreased by increasing $\mathrm{TiO}_{2}$ concentration in both types of acrylic resin. Impact strength of the conventional acrylic resin modified by $1 \%$ of additives significantly increased. The microhardness is significantly increased by addition of $5 \%$ of $\mathrm{TiO}_{2} \mathrm{Nps}$. The Incorporation of $\mathrm{TiO}_{2}$ nanoparticles into acrylic resins can adversely affect its flexural strength. Meanwhile, the impact

\footnotetext{
*On leave from Mechanical Engineering Department, Faculty of Engineering, Helwan University, Cairo, Egypt.

\#On leave from Mechanical Engineering Department, Faculty of Engineering, Benha University, Benha, Egypt.
} 
strength can be modified by small percentage of additives (abt. 1\%). This effect is directly correlated with the concentration of nanoparticles. On the other hand, concentrations of $\mathrm{TiO}_{2} \mathrm{Nps}(\mathrm{abt}$. $5 \%)$ positively affect the microhardness of both types of acrylic resin used in the present study.

\title{
Keywords
}

\author{
Titanium Dioxide, High Impact Acrylic Resin, Conventional Unmodified Acrylic Resin, Impact \\ Strength, Flexural Strength, Microhardness, Water Sorption
}

\section{Introduction}

Polymers composites have an important role in dental field because their distinctive features allow a wide range of clinical implementations, which are impossible with the use of other types of materials [1]. One of the commonly used polymers in dental filed is polymethylmethacrylate (PMMA), which uses either heat polymerized or self-polymerized acrylic resin. The popularity of acrylic resin is related mainly to its ease in manipulation, ease in finishing and polishing, as well as it needs inexpensive equipment [2]. Furthermore, the acrylic resin (PMMA) has good stability in the oral conditions and has high aesthetic quality. Unfortunately, until now the acrylic resin denture base material does not fulfill all the requirements of acceptable mechanical properties [3]. However, low mechanical properties against impact, bending, and fatigue are important issues to be addressed in order to improve acrylic polymers properties for removable orthodontic appliances and dentures [4] [5]. Many techniques have been used for improving mechanical properties such as chemical correction of polymeric structure by additives like polyethylene glycol dimethacrylate. The other useful method is to reinforce acrylic base composite by materials like fibers and particles [6] [7].

Although there are many types of nano-metals, $\mathrm{TiO}_{2}$ nanoparticles are increasingly used owing to the impressive features as nontoxicity, chemically inactive, low cost, high refractive index, antibacterial effect, corrosion resistant and high microhardness. Furthermore literature has also showed that nanoscale $\mathrm{TiO}_{2}$ reinforcement agents bring new optical, electrical, physiochemical properties attained at very low $\mathrm{TiO}_{2}$ content, which makes polymer- $\mathrm{TiO}_{2}$ nanocomposites a promising new class of materials. It can be anticipated that it will be commercially beneficial for widespread fields [8] [9]. Moreover $\mathrm{TiO}_{2}$ nanoparticles have been used as additives to biomaterials in order to induce antimicrobial properties [10]. Antimicrobial activities of $\mathrm{TiO}_{2}$ against Candida albicans, Staphylococcus aureus, Pseudomonas aeruginosa, Escherichia coli, Lactobacillus acidophilus, etc. have been proved by recent studies [11].

On the other hand, mechanical properties of acrylic resins are as much important, the flexural strength (FS) has achieved special concern. A standard minimal limit for flexural strength has been established for any acrylic resin types by ISO 20795-1(2008) international standard for dentistry base polymers [12] [13]. It has been stated that ultimate flexural strength of any polymerized materials shall not be less than $50 \mathrm{MPa}$. Therefore it is strongly recommended to evaluate the effects of any additive or modifier on mechanical properties of acrylic materials to avoid any deleterious effect which may reduce their strength to below standard level [10] [14].

Some authors reported that, the addition of $\mathrm{TiO}_{2}$ nanoparticles to PMMA will lead to a significant decrease in the porosity of the denture resin. This finding suggests that the metal oxide nanoparticles are suitable additives for the improvement of PMMA formulations since high porosities have been considered as a critical drawback for PMMA in prosthodontics applications [7].

Although, the study of $\mathrm{TiO}_{2}$-based nanocomposites is still in its infancy and much research remains to be carried out to explore improved synthesis techniques yielding the different nanocomposite structures and to fully understand the actual structure/properties relationships. This study aims to investigate the effect of addition of $\mathrm{TiO}_{2}$ nanoparticles on the acrylic resin properties, including flexural strength, impact strength, and microhardness.

\section{Materials and Methods}

Two types of heat- polymerized acrylic resins were used in this study(Vertex-Dental bv J.V. oldenbarneveltin 62 3705 HJ Zeist, Netherlands): 
1) Normal heat cure acrylic resin (Rapid simplified);

2) High impact acrylic resin (Implacryl).

$\mathrm{TiO}_{2}$ nanoparticles with an average diameter of $46 \mathrm{~nm}$ were purchased from the Nano technology center (Beni-Suef University, Beni-Suef city, Egypt). The parameters measured in this study were flexural strength, impact strength, microhardness.

\subsection{Sample Preparation}

The sample dimensions were selected according to ISO 20795-1(2008) for comparing the samples with the standard (Specimens' dimensions are shown in Table 1). To achieve smooth surface without porosity stainless steel mold with selected dimensions were used to form the acrylic samples. Two different concentrations of $\mathrm{TiO}_{2}$ by weight ( $1 \%$ and $5 \%$ ) were added into both types of heat-cure acrylic resin. The samples were processed with optimal condition according to manufacture instructions (2.1:0.95 Powder/monomer ratios).

Conventional packing method and water bath curing for 2 hours at $95^{\circ} \mathrm{C}$ and 150 bar. After polymerization, the flasks were bench cooled at room temperature for 30 minutes and then placed for 15 minutes under running water before opening, according to manufacturer's instructions. Specimens retrieved were inspected for any irregularity. Faulty specimens were discarded and final specimens were selected for each group. Resin specimens were then stored in water for 2 weeks before testing. Thirty specimens were used for each test [flexural strength, impact strength, and microhardness] with the total number of 90 specimens.

\subsection{Sample Grouping}

Three tests were carried out, each test contains 6 groups. In each group, 5 specimens were made. Table 2 shows groups' classifications.

\subsection{Flexural Strength (FS)}

Specimens were tested by 3-point bend test on Lloyd universal testing machine (Model LRX plus II, Fareham, England) at a cross head speed of $5 \mathrm{~mm} / \mathrm{min}$. For the 3-point bend test, a fixture was fabricated as shown in Figure 1.

The maximum force (F) necessary to produce fracture of the specimen was recorded in Newton $(\mathrm{N})$. The flexural strength Q was calculated in (MPa) for all specimens using Equation (1).

$$
Q=\frac{3 F I}{2 B H^{2}}
$$

Table 1. Specimens' dimensions adopted in present study.

\begin{tabular}{cc}
\hline Test & Specimen Dimension \\
Bending & $50 \mathrm{~mm} \times 10( \pm 0.2) \mathrm{mm} \times 3.0( \pm 0.2) \mathrm{mm}$ \\
Impact & $60 \mathrm{~mm} \times 6.0 \mathrm{~mm} \times 4.0 \mathrm{~mm}$ \\
Microhardness & $25 \mathrm{~mm} \times 10 \mathrm{~mm} \times 3( \pm 0.2) \mathrm{mm}$ \\
\hline
\end{tabular}

Table 2. Classification of the groups for each test.

\begin{tabular}{cc}
\hline Groups & Description \\
\hline NC & Conventional heat-cure acrylic resin (PMMA) without additives as control. \\
N1 & Conventional heat-cure acrylic resin (PMMA) with $1 \% \mathrm{TiO}_{2}$ oxide nano-fillers powder. \\
N5 & Conventional heat-cure acrylic resin (PMMA) with $5 \% \mathrm{TiO}_{2}$ oxide nano-fillers powder. \\
HC & High Impact heat-cure acrylic resin (PMMA) without additives as control. \\
H1 & High Impact heat-cure acrylic resin (PMMA) with $1 \% \mathrm{TiO}_{2}$ oxide nano-fillers powder. \\
H5 & High Impact heat-cure acrylic resin (PMMA) with $5 \% \mathrm{TiO}_{2}$ oxide nano-fillers powder. \\
\hline
\end{tabular}




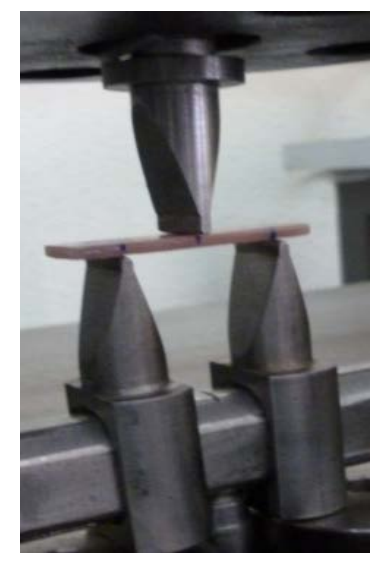

(a)

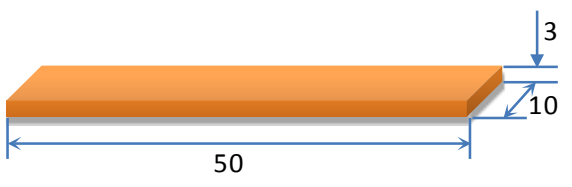

(b)

Figure 1. Flexural test; (a) fixture applied for the test and (b) flexural test specimen with dimensions.

where " $F$ " is the maximum/fracture force in Newton $(\mathrm{N})$, " $I$ " is the distance between the two supporting points in (mm); " $B$ " is the specimen width in (mm) and " $H$ " is the specimen height subjected to bending in (mm).

\subsection{Impact Strength}

After all specimens were stored in distilled water at $37^{\circ} \mathrm{C}$ for 24 hours, a notch was made in the middle of each specimen on one edge with $1.2 \mathrm{~mm}$ lengths using sand paper disk and taper steel file. The samples were tested with Pendulum impact tester (S.C. Dey \& Co., Calcutta, India) using IZOD method. The specimens were clamped at one end vertically, and the notched surface of the specimens facing the pendulum was used to break the specimens. The test was performed with 0.85 Jpendulum impact testing machine (bench type). The energy absorbed by the specimen up to fracture was detected and values obtained were tabulated for statistical analysis. The strength required to break the samples was calculated using Equation (2) [15].

$$
I S=\frac{E C(\mathrm{Kg} \cdot \mathrm{mm})}{h \cdot b A}
$$

where "IS" isimpact strength in $\left(\mathrm{kJ} / \mathrm{mm}^{2}\right)$, " $E C$ " is corrected energy absorbed by breaking the test specimen, " $b A$ " is the remaining thickness at notch tip, and " $h$ " is the specimen width.

\subsection{Microhardness}

Digital display Vickers microhardness tester (Model HVS-50, Laizhou Huayin Testing Instrument Co. Ltd., China) was used for determining surface microhardness. The specimens were polished by different types of sand papers from one surface. Microhardness tester was adjusted to a load of 50 gram for $10 \mathrm{sec}$. Four indentations were equally placed over a specimen surface to be not closer than $1 \mathrm{~mm}$ apart or to the margin of the specimens. Surface microhardness was obtained using Equation (3).

$$
V H N=1.854 \mathrm{~L} / \mathrm{d}^{2}
$$

where $V H N$ is Vickers microhardness number in $\mathrm{Kg} / \mathrm{m}^{2}, \mathrm{~L}$ is load in $\mathrm{Kg}$ and $\mathrm{d}$ is length of the diagonals in mm.

Calculated values for flexural strength, impact strength, and microhardness were statistically analyzed. Statistical analysis was done by applying SPSS software package (IBM Company, New York, US). Mean and standard deviation in each group were calculated and normal distribution curve was obtained and evaluated. Two way (Univariate test) and One way ANOVA was done for all tested groups for each type of acrylic resin followed by multiple comparison test (low significant difference LSD). Statistical significance was set at $\mathrm{P} \leq 0.05$. Independent $\mathrm{t}$ test was done between N1 group and $\mathrm{H} 1$ group for impact test.

\section{Results}

Flexural strength, impact strength and microhardness were measured for all specimens groups and values are 
listed in Table 3.

\subsection{Flexural Strength}

A comparison between mean flexural strength of the two types of PMMA is shown in Table 4 and Figure 2 for tested groups. ANOVA test showed statistically significant difference between groups of types of acrylic resin. NC group showed significantly highest mean flexural strength followed by $\mathrm{HC}$ and $\mathrm{H} 1$ containing $1 \% \mathrm{TiO}_{2}$ nanoparticles, then N1 specimen. N5 and H5 groups recorded the lowest flexural strength respectively. There were significant differences $(\mathrm{P}<0.05)$ between studied groups.

\subsection{Impact Strength}

Analysis of the impact strength data showed significant difference between the tested groups. There was significant decrease in the impact strength for groups reinforced with $\left(1 \%\right.$ and $\left.5 \% \mathrm{TiO}_{2}\right)$ when compared to control group as shown in Table 4 and Figure 3.

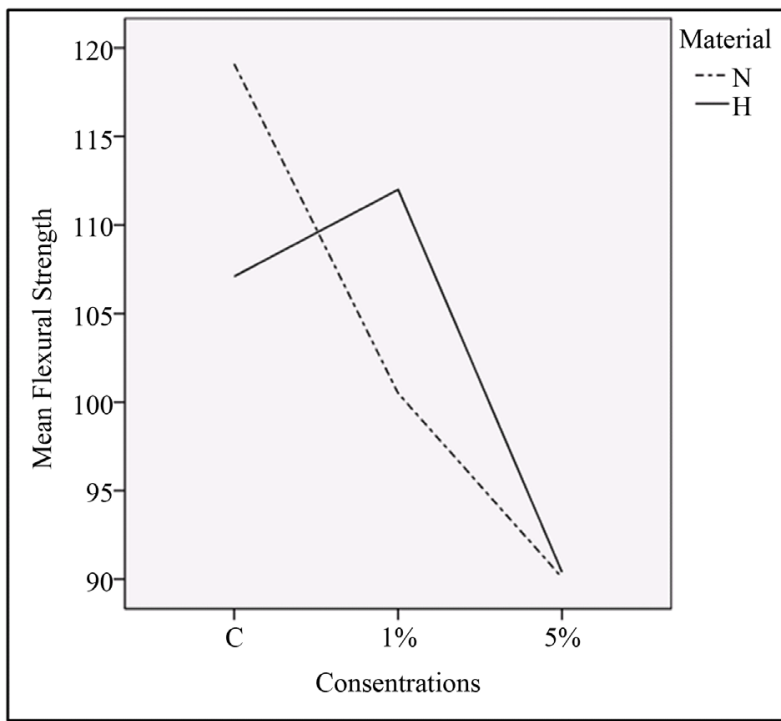

Figure 2. Chart of mean flexural strength (MPa) of the tested groups.

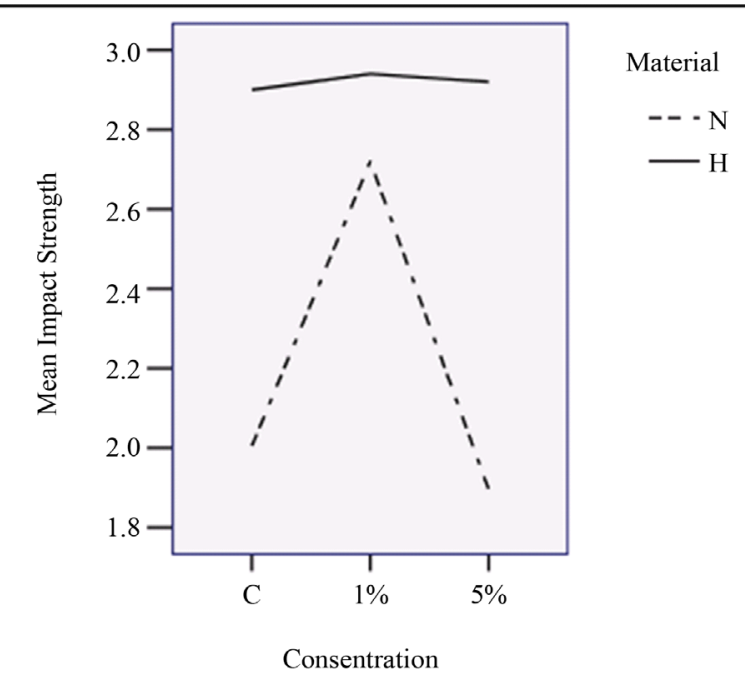

Figure 3. Chart of mean impact strength $\left(\mathrm{KJ} / \mathrm{m}^{2}\right)$ of the tested groups. 
Table 3. Summary for mechanical test results.

\begin{tabular}{|c|c|c|c|c|c|}
\hline No. & Material & Concentrations & Flexural strength & Impact strength & Microhardness \\
\hline 1 & & & 144.0 & 1.90 & 17.41 \\
\hline 2 & & & 111.0 & 1.90 & 18.19 \\
\hline 3 & & Control & 104.0 & 2.20 & 17.76 \\
\hline 4 & & & 112.5 & 2.05 & 17.58 \\
\hline 5 & & & 124.0 & 1.98 & 16.83 \\
\hline 6 & & & 105.0 & 2.10 & 17.70 \\
\hline 7 & & & 100.0 & 2.70 & 16.45 \\
\hline 8 & $\begin{array}{l}\text { Conventional } \\
\text { acrylic resin }\end{array}$ & $1 \%$ & 95.0 & 3.20 & 16.73 \\
\hline 9 & & & 102.5 & 2.65 & 16.90 \\
\hline 10 & & & 100.0 & 2.95 & 17.12 \\
\hline 11 & & & 91.0 & 2.00 & 21.61 \\
\hline 12 & & & 96.0 & 1.70 & 17.38 \\
\hline 13 & & $5 \%$ & 83.0 & 2.00 & 20.41 \\
\hline 14 & & & 87.0 & 1.85 & 19.50 \\
\hline 15 & & & 93.5 & 1.93 & 18.90 \\
\hline 16 & & & 126.0 & 2.80 & 17.94 \\
\hline 17 & & & 93.0 & 3.20 & 16.10 \\
\hline 18 & & Control & 107.0 & 2.60 & 19.58 \\
\hline 19 & & & 109.5 & 3.00 & 15.15 \\
\hline 20 & & & 100.0 & 2.90 & 17.02 \\
\hline 21 & & & 121.0 & 3.00 & 18.43 \\
\hline 22 & & & 107.0 & 2.70 & 15.28 \\
\hline 23 & $\begin{array}{l}\text { High impact } \\
\text { acrylic resin }\end{array}$ & $1 \%$ & 105.0 & 3.20 & 15.00 \\
\hline 24 & & & 113.0 & 2.85 & 15.27 \\
\hline 25 & & & 114.0 & 2.95 & 19.38 \\
\hline 26 & & & 100.0 & 2.10 & 20.56 \\
\hline 27 & & & 90.0 & 3.20 & 16.01 \\
\hline 28 & & $5 \%$ & 78.0 & 3.40 & 17.92 \\
\hline 29 & & & 89.0 & 3.15 & 21.21 \\
\hline 30 & & & 95.0 & 2.75 & 21.35 \\
\hline
\end{tabular}

Table 4. Mean flexural strength, impact strengthand microhardness values of all tested groups.

\begin{tabular}{|c|c|c|c|c|c|c|c|c|}
\hline & $\mathrm{NC}$ & N1 & N5 & \multirow{2}{*}{ P-value } & $\mathrm{HC}$ & $\mathrm{H} 1$ & H5 & \multirow{2}{*}{ P-value } \\
\hline & Mean SD & Mean SD & Mean SD & & Mean SD & Mean SD & Mean SD & \\
\hline $\begin{array}{l}\text { Flexural test } \\
\qquad(\mathrm{MPa})\end{array}$ & $119.67^{\mathrm{a}} \pm 15.66$ & $100.5^{\mathrm{b}} \pm 3.7$ & $90.1^{\mathrm{b}} \pm 5.1$ & $0.002^{*}$ & $107.1^{\mathrm{a}} \pm 16.56$ & $112^{\mathrm{a}} \pm 8.72$ & $90.4^{\mathrm{b}} \pm 11.02$ & $0.008^{*}$ \\
\hline $\begin{array}{l}\text { Impact test } \\
\left(\mathrm{KJ} / \mathrm{m}^{2}\right)\end{array}$ & $2^{a} \pm 0.17$ & $2.7^{\mathrm{b}} \pm 0.6$ & $1.9^{\mathrm{a}} \pm 0.2$ & $0.001^{*}$ & $2.90^{\mathrm{a}} \pm 0.3$ & $2.94^{\mathrm{a}} \pm 0.3$ & $2.92^{\mathrm{a}} \pm 0.7$ & $0.00^{*}$ \\
\hline $\begin{array}{l}\text { Microhardness } \\
\text { (VHN) }\end{array}$ & $17.55^{\mathrm{a}} \pm 0.5$ & $16.98^{\mathrm{a}} \pm 0.47$ & $19.56^{\mathrm{b}} \pm 1.6$ & $0.004^{*}$ & $17.16^{\mathrm{a}} \pm 1.71$ & $16.67^{\mathrm{a}} \pm 2.07$ & $19.41^{b} \pm 2.35$ & $0.02^{*}$ \\
\hline
\end{tabular}

* Significant at $\mathrm{P} \leq 0.05$; Means with different letters are significantly different according to LSD test. 


\subsection{Microhardness}

Both Table 4 and Figure 4 show the mean microhardness of tested groups. In both types of acrylic resin there is significant deference in microhardness between all groups by ANOVA test. The LSD multiple comparisons show a statistically no significant difference between control groups and 1\% groups in both types of acrylic resin in recorded values of microhardness. While the N5 and H5 recorded the highest values of Vicker's microhardness number.

\section{Discussion}

Fracture in an acrylic denture base is a common clinical problem. Therefore, numerous number of trials were done to improve the mechanical properties of PMMA, but they can be summarized in three ways: replacing PMMA with an alternative material; chemically modifying it; and reinforcing the PMMA with other materials like fibers or metals [16] [17].

In this investigation the authors principally aimed to assess possible changes in the mechanical properties of two types of PMMA namely conventional and high impact acrylic resin, in particular, the flexural strength (FS), impact strength, and microhardness through incorporating of $\mathrm{TiO}_{2}$ nano particles with two different concentrations $1 \%$ and $5 \%$. Up to the best knowledge of the authors, the most suitable concentration for the addition of different nano metals to the acrylic resin that can lead to the best properties is doubtful until now. Moreover, it was found that concentrations above 5\% have led to massive changes occurred in the color of acrylic [18]. Therefore, the two concentrations $1 \%$ and $5 \%$ were selected.

Flexural strength of denture base resin is considered the primary mode of clinical failure [19]. Based on flexural strength values obtained in the present study, it has been demonstrated that flexural strength would drop by addition of additive to acrylic resin since it acts as impurities especially with conventional acrylic resin [10]. This is in agreement with result obtained by Sodagar et al. [10]. In the contrary, adding $1 \% \mathrm{TiO}_{2}$ to $\mathrm{PMMA}$ could raise the flexural strength of the resin. These results may be attributed to dispersion of $\mathrm{TiO}_{2} \mathrm{Nps}$ in PMMA matrix which adversely affects degree of conversion which in turn leads to increase in the level of residual unreacted monomer that acts as plasticizer [20]. It is easily noted that the content of nano additives is of critical importance.

Impact results showed significant increase for conventional acrylic resin modified by $1 \% \mathrm{TiO}_{2} \mathrm{Nps}_{\text {. Statistical }}$ compression (independent $\mathrm{T}$ test) was done between the results of $1 \%$ conventional acrylic resin samples and the $1 \%$ samples of high impact resin. No significant difference was observed between both groups. Therefore, addition of $1 \% \mathrm{TiO}_{2} \mathrm{Nps}$ to conventional resin improves conventional resin impact strength to reach the high impact material. This achievement can reduce much cost by replacing the high impact material with conventional one.

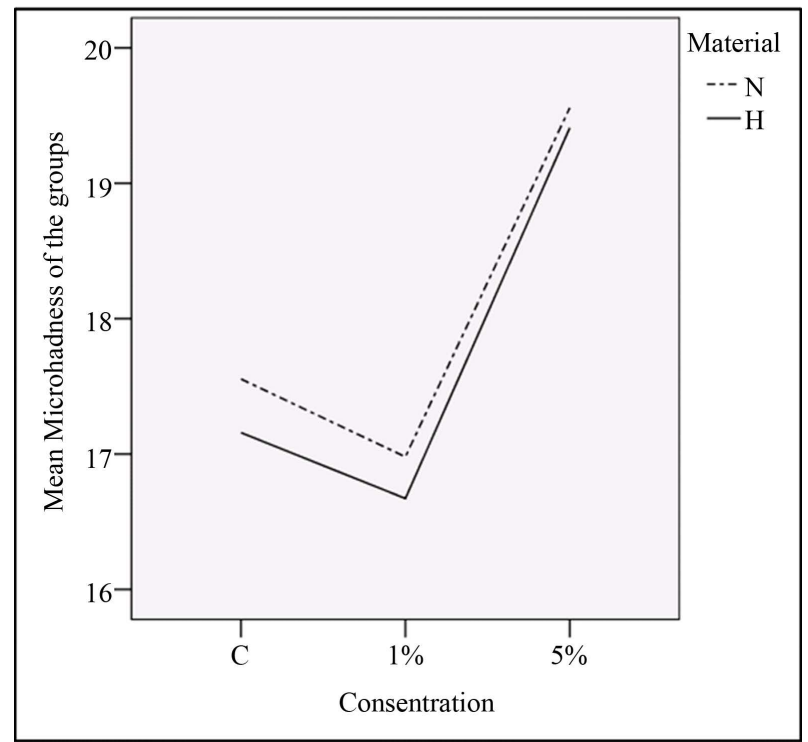

Figure 4. Chart of mean hardness (VHN) of the tested groups of PMMA. 
On the other hand, higher concentrations $\left(5 \% \mathrm{TiO}_{2}\right)$ will lead to impact strength deterioration of the resin material. This is attributed to higher filler content above saturation point at which the resin cannot incorporate further filler particles. Any attempt to add filler particles after reaching saturation of matrix leads to interruption in the resin matrix continuity and thus causing a decrease in the strength of reinforced specimens. These findings are consistent with those reported by different authors [21] [22].

Adding $1 \% \mathrm{TiO}_{2}$ decreased microhardness of both types of resin materials while adding $5 \% \mathrm{TiO}_{2}$ could enhance the microhardness of both types of resin materials to reach nearly identical microhardness values. This microhardness increase leads to higher wear resistance for the resin material as reported by some authors [23] [24]. Higher wear resistance can be benefitted in some dental applications such as occlusal splint appliances. In addition, the microhardness increase by adding $5 \% \mathrm{TiO}_{2}$ to the conventional acrylic resin material gives a chance to replace the high impact material with the conventional one which minimizes the total cost of denture base with about $60 \%-70 \%$.

\section{Conclusions}

From the present study, the following remarks could be drawn:

- Adding $1 \% \mathrm{TiO}_{2}$ could enhance the impact strength of the conventional resin material to reach high impact material.

- Adding $5 \% \mathrm{TiO}_{2}$ increased the microhardness values for conventional resin material to remarkable values.

- Addition of $\mathrm{TiO}_{2}$ Nps had an adverse effect on the flexural strength of conventional heat polymerized acrylic resin.

- The effect of $\mathrm{TiO}_{2}$ Nps on flexural strength of PMMA depended on several factors, including the type of acrylics and the concentrations of nano particles.

- Replacement of high impact resin material with conventional one having additives of $\mathrm{TiO}_{2}$ could be achieved based on economic considerations in the light of mechanical properties improvement.

- Further studies are needed to investigate the effect of other nanomaterials on mechanical and physical properties of PMMA.

\section{Acknowledgements}

The authors would like to express their sincere gratitude to Taif University for its funding of this research project (project number 1-435-3270).

\section{References}

[1] Elshereksi, N.W., Ghazali, M.J., Muchtar, A. and Azhari, C.H. (2014) Perspectives for Titanium-Derived Fillers Usage on Denture Base Composite Construction: A Review Article. Advances in Materials Science and Engineering, 2014, Article ID: 746252. http://dx.doi.org/10.1155/2014/746252

[2] Ahmed, M.A. and Ebrahim, M.I. (2014) Effect of Zirconium Oxide Nano-Fillers Addition on the Flexural Strength, Fracture Toughness, and Hardness of Heat-Polymerized Acrylic Resin. World Journal of Nano Science and Engineering, 4, 50-57. http://dx.doi.org/10.4236/wjnse.2014.42008

[3] Hamouda, I.M. and Beyari, M.M. (2014) Addition of Glass Fibers and Titanium Dioxide Nanoparticles to the Acrylic Resin Denture Base Material: Comparative Study with the Conventional and High Impact Types. Oral Health and Dental Management, 13, 107-112.

[4] Mowade, T.K., Dange, S.P., Thakre, M.B. and Kamble, V.D. (2012) Effect of Fiber Reinforcement on Impact Strength of Heat Polymerized Polymethyl Methacrylate Denture Base Resin: In Vitro Study and SEM Analysis. Journal of Advanced Prosthodontics, 4, 30-36. http://dx.doi.org/10.4047/jap.2012.4.1.30

[5] Vallo, C.I., Abraham, G.A., Cuadrado, T.R. and Román, J.S. (2004) Influence of Cross-Linked PMMA Beads on the Mechanical Behavior of Self-Curing Acrylic Cements. Journal of Biomedical Materials Research Part B: Applied Biomaterials, 70B, 407-416. http://dx.doi.org/10.1002/jbm.b.30054

[6] Sasaki, H., Hamanaka, I., Takahashi, Y. and Kawaguchi, T. (2015) Effect of Reinforcement on the Flexural Properties of Injection-Molded Thermoplastic Denture Base Resins. Journal of Prosthodontics. http://dx.doi.org/10.1111/jopr.12419

[7] Shirkavand, S. and Moslehifard, E. (2014) Effect of $\mathrm{TiO}_{2}$ Nanoparticles on Tensile Strength of Dental Acrylic Resins. Journal of Dental Research, Dental Clinics, Dental Prospects, 8, 197-203. 
[8] Reijnders, L. (2009) The Release of $\mathrm{TiO}_{2}$ and $\mathrm{SiO}_{2}$ Nanoparticles from Nanocomposites. Polymer Degradation and Stability, 94, 873-876. http://dx.doi.org/10.1016/j.polymdegradstab.2009.02.005

[9] Chatterjee, A. (2010) Properties Improvement of PMMA Using Nano $\mathrm{TiO}_{2}$. Journal of Applied Polymer Science, 18, 2890-2897. http://dx.doi.org/10.1002/app.32567

[10] Sodagar, A., Bahador, A., Khalil, S., Shahroudi, A.S. and Kassaee, M.Z. (2013) The Effect of $\mathrm{TiO}_{2}$ and $\mathrm{SiO}_{2} \mathrm{Nanopar}^{-}$ ticles on Flexural Strength of Poly(methyl methacrylate) Acrylic Resins. Journal of Prosthodontic Research, 57, 15-19. http://dx.doi.org/10.1016/j.jpor.2012.05.001

[11] Maneerat, C. and Hayata, Y. (2006) Antifungal Activity of $\mathrm{TiO}_{2}$ Photocatalysis against Penicillium expansum in Vitro and in Fruit Tests. International Journal of Food Microbiology, 107, 99-103. http://dx.doi.org/10.1016/j.ijfoodmicro.2005.08.018

[12] Aeran, H., Kumar, V., Uniyal, S. and Tanwer, P. (2015) Nanodentistry: Is Just a Fiction or Future. Journal of Oral Biology and Craniofacial Research, 5, 207-211. http://dx.doi.org/10.1016/j.jobcr.2015.06.012

[13] Elsaka, S.E., Hamouda, I.M. and Swain, M.V. (2011) Titanium Dioxide Nanoparticles Addition to a Conventional Glass-Ionomer Restorative: Influence on Physical and Antibacterial Properties. Journal of Dentistry, 39, 589-598. http://dx.doi.org/10.1016/j.jdent.2011.05.006

[14] Andreotti, A.M., Goiato, M.C., Moreno, A., Nobrega, A.S., Pesqueira, A.A. and dos Santos, D.M. (2014) Influence of Nanoparticles on Color Stability, Microhardness, and Flexural Strength of Acrylic Resins Specific for Ocular Prosthesis. International Journal of Nanomedicine, 9, 5779-5787.

[15] Abdulwahhab, S.S. (2013) High-Impact Strength Acrylic Denture Base Material Processed by Autoclave. Journal of Prosthodontic Research, 57, 288-293. http://dx.doi.org/10.1016/j.jpor.2013.08.004

[16] Kim, S.-H. and Watts, D.C. (2004) The Effect of Reinforcement with Woven E-Glass Fibers on the Impact Strength of Complete Dentures Fabricated with High-Impact Acrylic Resin. The Journal of Prosthetic Dentistry, 91, 274-280. http://dx.doi.org/10.1016/j.prosdent.2003.12.023

[17] Jagger, D.C., Harrison, A. and Jandt, K.D. (1999) The Reinforcement of Dentures. Journal of Oral Rehabilitation, 26, 185-194. http://dx.doi.org/10.1046/j.1365-2842.1999.00375.x

[18] Shi, J.M., Bao, Y.Z., Huang, Z.M. and Weng, Z.X. (2004) Preparation of Poly (Methyl Methacrylate)/Nanometer Calcium Carbonate Composite by in Situ Emulsion Polymerization. Journal of Zhejiang University. Science, 5, 709-713.

[19] Chitchumnong, P., Brooks, S.C. and Stafford, G.D. (1989) Comparison of Three- and Four-Point Flexural Strength Testing of Denture-Base Polymers. Dental Materials, 5, 2-5.

[20] Shibata, T., et al. (2007) Antifungal Effect of Acrylic Resin Containing Apatite-Coated $\mathrm{TiO}_{2}$ Photocatalyst. Dental Materials Journal, 26, 437-444. http://dx.doi.org/10.4012/dmj.26.437

[21] Braden, M. (1988) Some Aspects of the Chemistry and Physics of Dental Resins. Advances in Dental Research, 2, 9397.

[22] Vipul Asopa, S.S., Khandelwal, M., Sharma, V., Asopa, S.S. and Kaira, L.S. (2015) A Comparative Evaluation of Properties of Zirconia Reinforced High Impact Acrylic Resin with That of High Impact Acrylic Resin. The Saudi Journal for Dental Research, 6, 146-151. http://dx.doi.org/10.1016/j.sjdr.2015.02.003

[23] Vojdani, M., Bagheri, R. and Khaledi, A.A.R. (2012) Effects of Aluminum Oxide Addition on the Flexural Strength, Surface Hardness, and Roughness of Heat-Polymerized Acrylic Resin. Journal of Dental Sciences, 7, 238-244. http://dx.doi.org/10.1016/j.jds.2012.05.008

[24] Lee, S.Y., Lai, Y.L. and Hsu, T.S. (2002) Influence of Polymerization Conditions on Monomer Elution and Microhardness of Autopolymerized Polymethyl Methacrylate Resin. European Journal of Oral Sciences, 110, 179-183. http://dx.doi.org/10.1034/j.1600-0722.2002.11232.x 


\section{Submit or recommend next manuscript to SCIRP and we will provide best service for you:}

Accepting pre-submission inquiries through Email, Facebook, Linkedin, Twitter, etc A wide selection of journals (inclusive of 9 subjects, more than 200 journals)

Providing a 24-hour high-quality service

User-friendly online submission system

Fair and swift peer-review system

Efficient typesetting and proofreading procedure

Display of the result of downloads and visits, as well as the number of cited articles

Maximum dissemination of your research work

Submit your manuscript at: http://papersubmission.scirp.org/ 